\title{
Multi-Effect Solar Water Still with Evaporation Pressure Self-Reduction Capability
}

\author{
Nabil Elsharif and Khamid Mahkamov
}

\begin{abstract}
The objective of this paper is to investigate the operation of multi-effect water still coupled to an evacuated heat pipe tube solar collector and small fluid piston energy converter. The solar collector is used to provide heating of the saline water in the still and also to drive the fluid piston converter. This converter operates as a pump to evacuate air from the still and reduce pressure inside the still which would result in the increased saline water evaporation rate. The mathematical model of operation of the proposed water desalination system was developed using a set of equations to describe the mass and energy balance for each stage of the still. A simulation was carried out in Matlab/Simulink environment in order to calculate the distillate productivity and temperatures in all stages of the still. The preliminary results demonstrate that the total productivity of the multi-effect still is strongly affected by the pressure inside the still. Currently, the physical model of the system being assembled on the test rig to validate theoretical results.
\end{abstract}

Index Terms-Fluid piston converter, multi-effect water solar still, solar desalination, solar energy.

\section{INTRODUCTION}

Production of potable water by means of conventional seawater desalination processes consumes a huge amount of carbon-rich fossil fuel [1]. Therefore, taking into account the high energy consumption and the environmental impact of burning carbon-rich fuels, the coupling of solar energy to seawater desalination to produce potable water is considered as a highly promising alternative.

Solar still is one of the most popular desalination technologies and extensive investigations have been conducted on various designs in order to improve stills effectiveness and productivity. Experimental study was carried out on a single basin, single slope double condensing chamber solar still [2]. Experimental evaluation of the effect of the inclination angle of the internal and external reflectors on the performance of a traditional solar still at different seasons was conducted in [3] .A single basin still with a suspended absorber was fabricated and investigated by [4], and [5] and a significant improvement in the still productivity was observed. The performance of single basin still was enhanced when an external solar collector was coupled to the still [6]. Theoretical and experimental investigations on the performance of a single slope solar still coupled to an evacuated tube collector and storage tank. The

Manuscript received March 19, 2017; revised August 1, 2017.

Nabil Elsharif and Khamid Mahkamov are with Mechanical and Construction Department, Faculty of Engineering and Environment, Northumbria University at Newcastle, Newcastle Upon Tyne, UK (e-mail: nabil.elsharif@northumbria.ac.uk). results indicated that the water production rate doubled compared to that of still-only solar systems [7].

Additionally, the performance of a single basin solar still with and without vacuum was investigated theoretically and experimentally by [8]. The results showed that the performance of the still was enhanced when working in low pressure environment. The effect of the design parameters on the performance of the multi-effect solar still coupled with evacuated tube solar collector was investigated theoretically and experimentally by [9]. A multi-stage evacuated solar desalination system was described by [10], which was investigated under low pressure conditions.

\section{Physical And Mathematical Model}

The schematic diagram of the evacuated multi-effect still, which is the subject of the present investigation, is schematically shown in Fig. 1. The system consists of two parts: the first part is a four-stages still coupled to an evacuated tube solar collector, which was described in details in [11]. The second part is a novel modification, where a small fluid piston energy converter is connected to the still in order to evacuate air from the still and reduce its pressure. Details of the fluid piston and its mathematical model were presented in [12], [13].

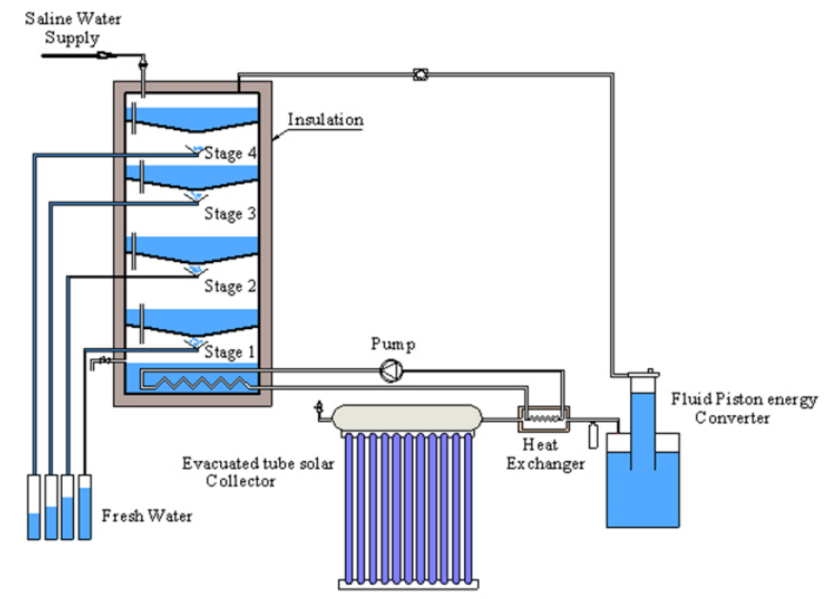

Fig. 1. Schematic diagram of evacuated multi-effect solar still.

The solar collector is used to provide heating of the saline water in the still in order to enhance evaporation process and to drive the fluid piston converter. The mathematical model was developed based on a numerical model to simulate the fresh water productivity and temperature in each stage. The proposed model was obtained by applying the energy and mass balance equations for each stage of the multi-stage desalination system as shown in Fig. 2. Assumptions made when developing the model are as follows: 
- Due to the absence of non-condensable gases and the low-temperature difference between the adjacent stages, heat is exchanged between the hot water bed and the condensing surface by evaporation and condensation processes. Heat transfer due to natural convection and radiation can be considered as negligible.

- All the amount of evaporated water is collected and equal to the distillate yield in every stage.

- The distillate leaves the stage with the temperature equal to that of the condensing surface.

In order to calculate the temperature of water and productivity in each stage, the energy and mass conservation equations were written in the form of ordinary differential equations as presented in [9].

The first stage:

$$
\dot{Q}_{H}-\dot{m}_{e 1}\left(h_{f g 1}^{*}+c_{p} T_{c 1}\right)=M_{s 1} C_{p} \frac{d T_{s 1}}{d t}+\dot{Q}_{\text {losses } 1}
$$

The second stage:

$$
\begin{gathered}
\dot{m}_{e 1} h_{f g 1}^{*}-\dot{m}_{e 2}\left(h_{f g 2}^{*}+c_{p} T_{c 2}\right)=M_{s 2} C_{p} \frac{d T_{s 2}}{d t}+ \\
\dot{Q}_{\text {losses } 2}
\end{gathered}
$$

The third stage:

$$
\begin{gathered}
\dot{m}_{e 2} h_{f g 2}^{*}-\dot{m}_{e 3}\left(h_{f g 3}^{*}+c_{p} T_{c 3}\right)=M_{s 3} C_{p} \frac{d T_{s 3}}{d t}+ \\
\dot{Q}_{\text {losses } 3}
\end{gathered}
$$

The fourth stage:

$$
\begin{gathered}
\dot{m}_{e 3} h_{f g 3}^{*}-\dot{m}_{e 4}\left(h_{f g 4}^{*}+c_{p} T_{c 4}\right)=M_{s 4} C_{p} \frac{d T_{s 4}}{d t}+ \\
\dot{Q}_{\text {losses } 4}
\end{gathered}
$$

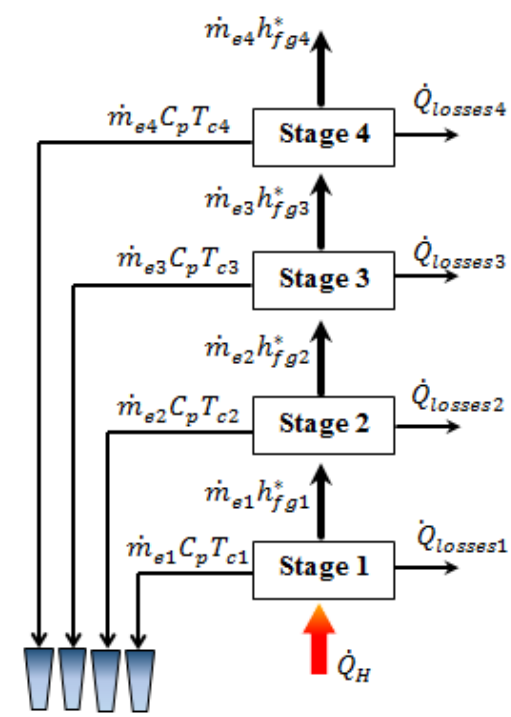

Fig. 2. Energy balance diagram for a multi-effect solar still.

where $\dot{Q}_{H}$ is the heat input (W), $\dot{m}_{e}$ is the vapour mass flow rate in each stage $(\mathrm{kg} / \mathrm{s}), h_{f g}^{*}$ is The water refined value of latent heat of vaporization $(\mathrm{J} / \mathrm{kg}), C p$ is specific heat of water $\left(\mathrm{J} /(\mathrm{kg} . \mathrm{K}) . T_{s}\right.$ is the saline water temperature in each stage $\left({ }^{\circ} \mathrm{C}\right), T_{c}$ is the condensing surface temperature in each stage $\left({ }^{\circ} \mathrm{C}\right) . M_{s}$ is the mass of saline water in each stage $(\mathrm{kg})$. $t$ is time (s). Mass conservation equation for each stage is given by:

$$
\frac{d M_{s i}}{d t}=-\dot{m}_{e i}
$$

The walls of the stills are insulated and heat losses through the walls of each stage $\dot{Q}_{\text {lossesi }}$ can be estimated based on the heat conductivity of the insulation material and the temperature of the water bed and the ambient temperature. The latent heat of vaporization and the modified latent heat of vaporization of water for each stage can be calculated as suggested in [10]:

$$
h_{\mathrm{fgi}}=1000 \times\left[3161.5-2.41\left(T_{\mathrm{av}}+273\right)\right]
$$

where:

$$
\begin{gathered}
T_{a v}=\frac{T_{s i}+T_{c i}}{2} \\
h_{f g i}^{*}=h_{f g i}+0.68 \times C_{p i}\left(T_{s i}-T_{c i}\right)
\end{gathered}
$$

The specific heat capacity of water in each stage $C_{p i}$ is given as a function of the stage temperature as suggested in [14]:

$$
C_{p i}=1000 \times\left[4.2101-0.0022 T_{s i}+5 \times 10^{-5} T_{s i}^{2}-\right.
$$

Due to the extremely intricate phenomena of combined mass and heat transfer inside evacuated multi-stage solar desalination still systems, the modified Grashof number is defined as in [15]:

$$
G r_{i}^{*}=\frac{g B_{i} \rho_{m i}^{2} L^{3} \Delta T_{i}^{*}}{\mu_{m i}^{2}}
$$

where, $\Delta T_{i}^{*}$ is the modified temperature difference for each stage, given by

$$
\Delta T_{i}^{*}=\left(T_{s i}-T_{c i}\right)+\frac{T_{s i}\left(P_{v s i}-P_{v c i}\right)\left(M_{a}-M_{v}\right)}{M_{a} P_{o}-P_{v s i}\left(M_{a}-M_{v}\right)}
$$

The partial saturation pressure of water vapour inside each stage, $P_{v i}$, and the convective heat transfer coefficient can be calculated as proposed in $[15,16]$ :

$$
N u=\mathrm{C}(R a)^{n}
$$

The values of the constants $C$ and $n$ can be assumed to be equal to 0.2 and 0.26 , respectively, which can be applied for a broad range of Rayleigh number, namely $3.5 \times 103<\mathrm{Ra}$ $<106$ as in [10]. Thus equation (12) can be rewritten as follows:

$$
\frac{h_{c v i} L}{k_{m i}}=0.2\left(G r_{i}^{*} P r_{i}\right)^{0.26}
$$

The convective heat transfer coefficient for each stage can be calculated by the following equation:

$$
\begin{array}{r}
h_{C V i}= \\
C k_{m i} L^{3 n-1}\left(\frac{g \rho_{m i} \beta_{i}}{\mu_{m i} \alpha_{m i}}\right)^{n}\left[\left(T_{s i}-T_{c i}\right)+\right. \\
\text { TsiPvsi-PvciMa-MvMaPo-PvsiMa-Mvn }
\end{array}
$$

All the values of thermo-physical properties of the vapour-air mixture can be estimated as proposed by [15], [16]. The distillate production rate for each stage can be calculated using the formula presented in [16]:

$$
\dot{m}_{\mathrm{ei}}=\frac{A_{s} h_{c v i}}{\left(\rho_{m i} c_{p m i}\right)} \frac{P_{o}}{P_{A M i}} \frac{M_{v}}{R}\left(\frac{P_{v s i}}{T_{s i}}-\frac{P_{v c i}}{T_{c i}}\right) L e_{i}^{-2 / 3}
$$




\section{METHODOLOGY}

The numerical simulation process was carried out in Matlab/Simulink environment in order to simulate the operation of multi-effect solar still by solving the energy and mass conservation equations of the above mathematical model, as shown in Fig. 3.

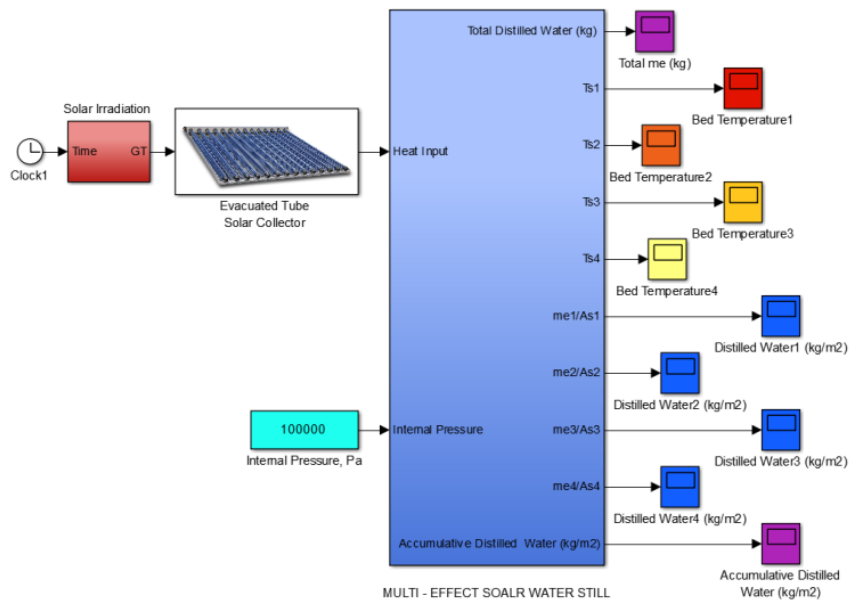

Fig. 3. The Simulink model of the multi-effect solar water still.

The developed simulation process takes into consideration the influence of the variation of the thermosphysical properties of the binary mixture of dry air and water vapour, the partial pressure of the vapour on the evaporating and condensing surfaces and also the variation of the average distance between these two surfaces and, moreover, it accounts for the heat losses through the walls of the still. The results obtained from this model provide information on the distillate productivity and temperatures for every stage and also for the still's overall productivity.

\section{RESUlTS AND DisCUSSION}

The operation of the multi-effect water still was simulated for the conditions of a typical mid-summer day in the Middle East region as presented in [9]. In order to examine the accuracy of the present model on prediction of the stage temperatures and distillate productivity, the model was validated comparing its results and that in [9] for the atmospheric pressure. The initial water bed temperatures were assumed to be $12.5{ }^{\circ} \mathrm{C}, 12.4{ }^{\circ} \mathrm{C}, 12.3{ }^{\circ} \mathrm{C}, 12.2{ }^{\circ} \mathrm{C}$, in the first, second, third and fourth stages respectively. Fig. 4 shows the comparison of the cumulative yield of the proposed model and the model in [9].

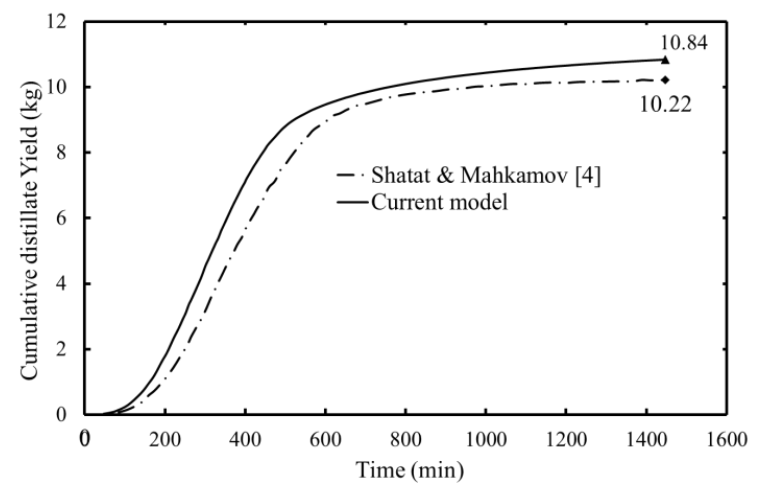

Fig. 4. Comparison of theoretical cumulative distillate productivity of present model with the theoretical distillate yield in [9].
There is a good agreement in stage temperatures and the total cumulative distillate yield predicted by the present model is $6.1 \%$ higher than that in [9]. The deviation between the theoretical results of the current model and of that presented in [9] is the result of using in this present study the thermos-physical properties of the binary mixture of dry air and water vapour.

Fig. 5 demonstrates the variation of the total cumulative distillate yield with the pressure level inside the solar still. The daily distillate yield of the evacuated multi-effect solar still was found to be $39.9 \mathrm{~kg} / \mathrm{m}^{2}$ at a pressure level of 0.03 bar whilst the total cumulative yield at atmospheric pressure was $25.95 \mathrm{~kg} / \mathrm{m}^{2}$. The still productivity decreased as the pressure level increased due to the lower evaporation rates.

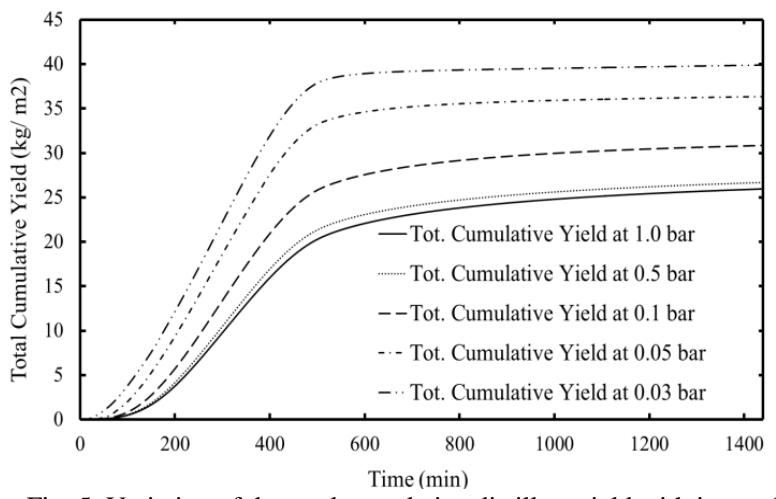

Fig. 5. Variation of the total cumulative distillate yield with internal pressure.

The productivity of the multi-effect solar still is significantly affected by the pressure level inside the still as shown in Fig. 6. Although the total cumulative distillate yield increases with decreasing the internal pressure it is obvious that the effect becomes more dominant at pressure levels below 0.5 bar.

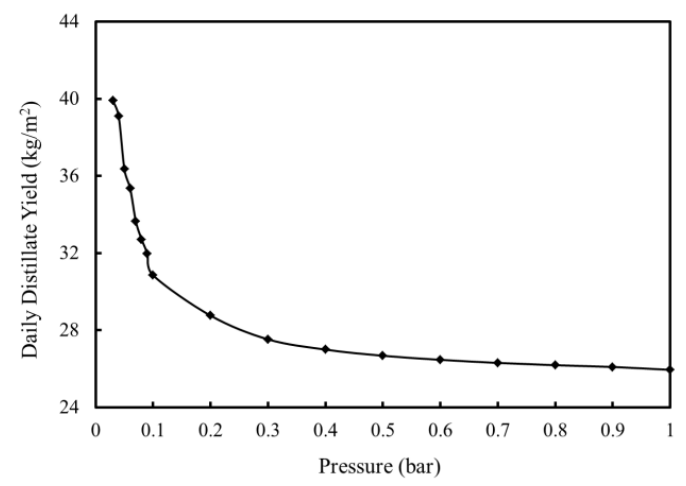

Fig. 6. Effect of internal pressure level on the total daily distillate yield.

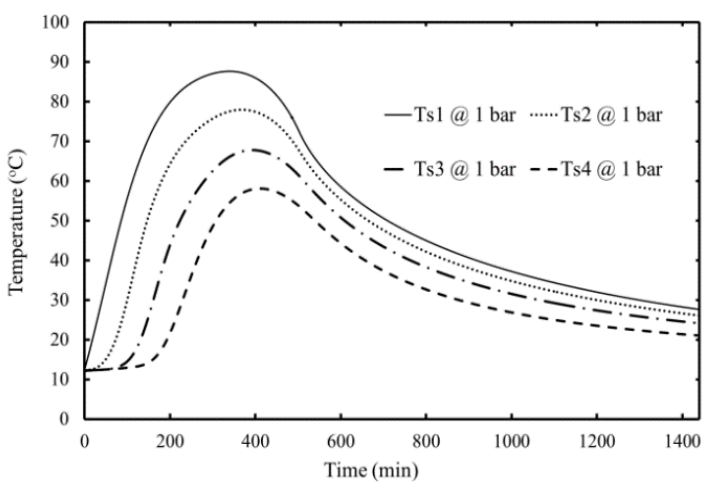

Fig. 7. Effect of internal pressure level on the stage temperatures. 
The effect of the internal pressure level on the stage temperatures was also investigated. Fig. 7 and Fig. 8 show the stage temperatures at internal pressure levels of 1 and 0.03 bar respectively. It can be seen that the maximum temperature is observed in the first stage and it can reach about $87{ }^{\circ} \mathrm{C}$ at the atmospheric pressure whilst this temperature is about $32{ }^{\circ} \mathrm{C}$ at the 0.03 bar pressure level.

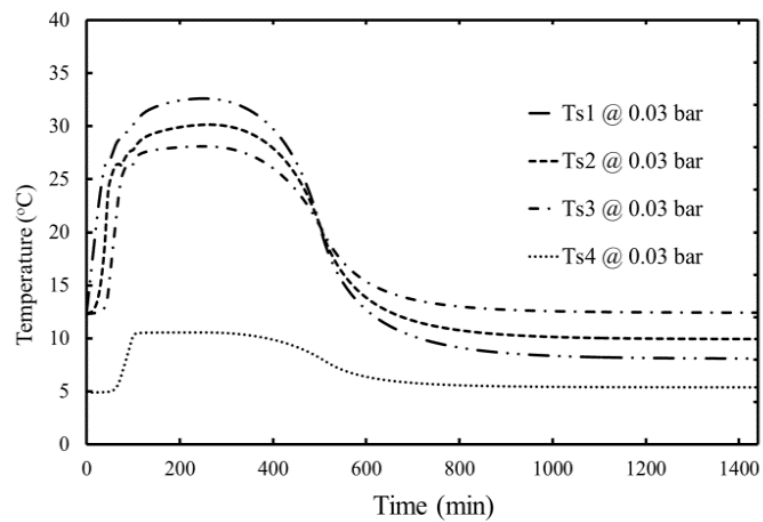

Fig. 8. Effect of internal pressure level on the stage temperatures.

\section{CONCLUSION}

In this study, the performance of an evacuated multieffect solar still, coupled to evacuated heat pipe tube solar collector and small fluid piston energy converter, was theoretically investigated. The mathematical model of this system was developed and the simulation of the still's operation was performed using Matlab/Simulink program. Preliminary results show that the pressure inside the multieffect solar still plays a crucial role on the still productivity and the stage temperatures.

Currently, the physical model of the system is being assembled. It includes the prototype of conventional multistage solar still connected to an evacuated tube solar collector and fluid piston energy converter. An experimental investigation will be conducted to validate the theoretical results in the near future.

\section{REFERENCES}

[1] A. D. Khawaji, I. K. Kutubkhanah, and J.-M. Wie, "Advances in seawater desalination technologies," Desalination, vol. 221, pp. 47-69, 3/1/2008.

[2] G. N. Tiwari, A. Kupfermann, and S. Aggarwal, "A new design for a double-condensing chamber solar still, " Desalination, vol. 114, pp. 153-164, Dec. 15, 1997.

[3] A. J. N. Khalifa and H. A. Ibrahim, "Effect of inclination of the external reflector on the performance of a basin type solar still at various seasons," Energy for Sustainable Development, vol. 13, pp. 244-249, 2009

[4] P. Valsaraj, "An experimental study on solar distillation in a single slope basin still by surface heating the water mass," Renewable Energy, vol. 25, pp. 607-612, 2002.

[5] A. A. El-Sebaii, S. Aboul-Enein, and E. El-Bialy, "Single basin solar still with ba,ffle suspended absorber," Energy Conversion and Management, vol. 41, pp. 661-675, 2000.
[6] H. Mousa and M. Abu Arabi, "Desalination and hot water production using solar still enhanced by external solar collector," Desalination and Water Treatment, vol. 51, pp. 1296-1301, 2013.

[7] K. Sampathkumar and P. Senthilkumar, "Utilization of solar water heater in a single basin solar still - An experimental study," Desalination, vol. 297, pp. 8-19, 2012.

[8] M. K. Gnanadason, P. S. Kumar, G. Sivaraman, and J. E. S. Daniel, "Design and performance analysis of a modified vacuum single basin solar still," Smart Grid and Renewable Energy, vol. 2, pp. 388-395, 2011.

[9] M. I. M. Shatat and K. Mahkamov, "Determination of rational design parameters of a multi-stage solar water desalination still using transient mathematical modelling," Renewable Energy, vol. 35, pp 52-61, 1// 2010.

[10] K. S. Reddy, K. Ravi Kumar, Tadhg S. O'Donovan, and T. K. Mallick, "Performance analysis of an evacuated multi-stage solar water desalination system," Desalination, vol. 288, pp. 80-92, 2012

[11] Kh. Mahkamov and J. S. Akhatov, "Experimental study of the performance of multieffect solar thermal water desalination system," Applied Solar Energy, vol. 44, pp. 31-34, 2008.

[12] K. Mahkamov, G. Hashem, B. Belgasim, and I. Mahkamova, "A novel solar cooling system based on a fluid piston convertor," presented at the 16th International Stirling Engine Conference, ISEC2014 Bilbao, Spain, 2014

[13] K. Mahkamov, E. Orda, B. Belgasim, and I. Makhkamova, "A novel small dynamic solar thermal desalination plant with a fluid piston converter," Applied Energy, vol. 156, pp. 715-726, 2015.

[14] I. W. Eames, G. G. Maidment, and A. K. Lalzad, "A theoretical and experimental investigation of a small-scale solar-powered barometric desalination system," Applied Thermal Engineering, vol. 27, pp. 1951-1959, 2007.

[15] P. T. Tsilingiris, "The influence of binary mixture thermophysical properties in the analysis of heat and mass transfer processes in solar distillation systems," Solar Energy, vol. 81, pp. 1482-1491, 2007.

[16] P. T. Tsilingiris, "Modeling heat and mass transport phenomena at higher temperatures in solar distillation systems - The ChiltonColburn analogy," Solar Energy, vol. 84, pp. 308-317, 2010.

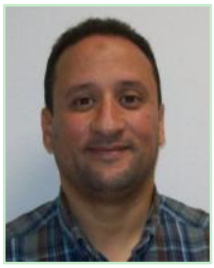

Nabil Elsharif was born in Tripoli, Libya, on March 8, 1971. He received the B.Sc. and the M.Sc. degrees in mechanical engineering from Benghazi University, Benghazi, Libya, in 1995 and 2008, respectively.

In 2010, he joined the Department of Mechanical Engineering at the Faculty of Engineering, Benghazi University, Libya, as an assistant lecturer. $\mathrm{He}$ is currently a $\mathrm{PhD}$ student in Mechanical and Construction Department at Faculty of Engineering and Environment at University of Northumbria at Newcastle, Newcastle, UK.

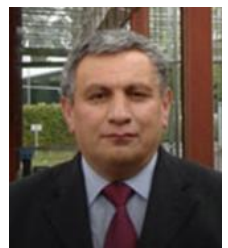

Khamid Mahkamov has MEng and $\mathrm{PhD}$ in mechanical engineering from Bauman Moscow Technical University in the field of Heat Engines. Prior to joining Northumbria University in 2011 he worked in the Academy of Sciences (USSR, 13 years), at Leeds University (Research Fellow, 2 years) and in the Energy Group of the School of Engineering and Computing Sciences of Durham University ( 9 years) where he held various academic positions.

Professor Mahkamov is a member of Editorial Board of the Journals of Renewable Energy (Elsevier) and Energetika - Proceedings of CIS Higher Education Institutions (Minsk, Belarus). $\mathrm{He}$ is also a member of International Council for Stirling Cycle Machines and a part of Membership Committee of Energy Institute (UK).

His research interets are focused on Thermo-Mechanical Conversion of Renewable Energy sources. 